\begin{tabular}{c} 
Volume and Issues Obtainable at Center for Sustainability Research and Consultancy \\
Journal of Business and Social Review in Emerging Economies \\
ISSN: 2519-089X (E): 2519-0326 \\
Volume 5: No. 1, June 2019 \\
JSRᄃ \\
Journal homepage: www.publishing.globalcsrc.org/jbsee \\
\hline
\end{tabular}

\title{
Women in Nigeria Labour Congress: A Comparative Study of the Northern and Southern Regions
}

\author{
${ }^{1}$ Mustapha Alhaji Ali, ${ }^{2}$ Ummu Atiyah Ahmad Zakuan, ${ }^{3}$ Mohammad Zaki Bin Ahmad \\ ${ }^{1}$ Department of Political Science and Administration. Yobe State University, Damaturu. Nigeria. \\ mustaphaalhajiali2@gmail.com:alimustapha07@gmail.com \\ ${ }^{2}$ Ghazali Shafie Graduate School of Government College of Law, Government and International Studies School of \\ International Studies (SOIS),Universiti of Utara Malaysia. hannahadham1212@gmail.com \\ ${ }^{3}$ Ghazali Shafie Graduate School of Government College of Law, Government and International Studies School of \\ International Studies (SOIS),Universiti of Utara Malaysia. mohdzaki@uum.edu.my
}

\begin{tabular}{ll}
\hline \multicolumn{1}{c}{ ARTICLE DETAILS } & ABSTRACT \\
\hline History & The paper examined the position of women participation in NLC of \\
Revised format: May 2019 & Northern and the Southern regions and explored the mechanisms NLC put \\
Available Online: June 2019 & in place to empower women in the Northern and Southern regions of \\
& Nigeria. \\
This paper is qualitative in nature. Data were obtained through the \\
Keywords & primary and secondary source of data collection. Contrast analysis \\
Nigeria, Northern, Regions, & approach was employed in comparing the position of women participation \\
Southern, Women & and empowerment in the NLC of the Northern and Southern regions of \\
& Nigeria. All data acquired were thematically analyzed using MAXQDA \\
JEL Classification: & Software Version 2018. \\
Th0, O57, J21 & This paper is a Case study because it provides the researcher with an in- \\
& depth understanding of the social phenomenon. \\
& Empowerment theory and the liberal feminist theory were used to explain \\
the topic under study. This is because the postulations of these theories & centered on equality between both genders in all societies. \\
The study found that the position of women participation and \\
empowerment in the NLC of the Northern region of Nigeria is low, \\
because of patriarchal nature of the region, compared to the position of \\
women participation and empowerment in NLC of the Southern region. It \\
further added that women participation in the NLC of both regions is \\
strong and healthy development. \\
The paper recommended that women should be empowered educationally \\
and allowed to hold managerial positions. It, in addition, suggested that \\
parents and religious leaders should advise women from religious and \\
parental points of view to participate actively in NLC of both regions.
\end{tabular}

(C) 2019 The authors, under a Creative Commons Attribution-

NonCommercial 4.0

Corresponding author's email address: mustaphaalhajiali2@gmail.com

Recommended citation: Ali, M.A., Zakuan, U. A. A. and Ahmad, M. Z. B. (2019). Women in Nigeria Labour Congress: A Comparative Study of the Northern and Southern Regions. Journal of Business and Social Review in Emerging Economies, 5 (1), 135-148

DOI: $10.26710 /$ jbsee.v5i1.654 


\section{Introduction}

The formation of the Nigerian Labour Congress (NLC) is targeted at ensuring a forum that protects workers' rights and interest. This informed the establishment of NLC in 1978 with the purpose of engaging the employer on sustaining employee welfare. Since its inception, NLC which cut across all states within Nigeria has been able to engage the Nigerian government on various issues affecting workers in the country.

NLC is the central labour union in Nigeria and is the umbrella of all sub-unions. It is recognized by Decree No. 44 of the 1976 Constitution as the sole representative of all unions in the nation. NLC is made up of 43 unions (Wabba, 2017). It has national executives and secretariats as well as states councils in all the 36 states in the country. It was created in 1978, after the unification of four unions, namely: Labour Unity Front (LUF), United Labour Congress (ULC), Nigeria Trade Union Congress (NTUC), and Nigeria Workers Council (NWC). Many associated unions were modernized into 43 unions that are formed to protect the rights and interests of their fellow members, and also to mediate between the government and the civil servants (NLC Reports, 2016; Wabba, 2017).

The major obligation of the NLC is to consolidate, train, unionize all groups of the nation workforces; protect and spread the governmental, economic, cultural and social rights and privileges of Nigerian employees; liberate and unite Nigerian labour and individuals from all forms of abuse and marginalization; attain gender fairness in all places of services; support and expand the links and influences among Nigerian employees and the natural associates in and outside the Nation and; lead the struggle for the changing of country into a fair, caring and independent state (Wabba, 2017; NLC, 2017).

The labour union prepares individuals for nationalist movements and remove the wide gap between the elites and the masses in Nigerian. It raises some questions about access to health services, education, and other welfare packages. It dares authoritarian inclinations, demonstrated by the call to form a national government in which authorized disagreement was eliminated and by the Protective Imprisonment Act of the 1960s, and the over-all subjugation by the military forces in the 1980s (Aiyede, 2004)

There are numerous authorized laws, state and global declarations in favour of gender equality rights, which are related to economic, political, and social reimbursements, without any form of subjugation because of any unfair principles of class, gender or race. Still, women are subjugated in several economic sectors on the Nigerian national economy. Furthermore, since the 1976-85 declaration as the United Nations Period for Women, it has been presumed that women in various places of work will develop much interest and take part vigorously in labour activities. Thus, this paper examined women participation in labour activities of the Northern and Southern regions of Nigeria.

Over the years, women are advocating for equal rights in participation in politics and labour unionism of their choice. They have been relegated to subordinate positions for a long time. Their struggle over values or claims to status and power between them and their male counterparts become apparent. Women want to see a situation where political divisions are minimized. Thus, fostering great collaboration between women and males in politics and decision-making activities is pertinent.

However, Mbamalu (2016) and Allen (1972) disclosed that women marginalization began in Nigeria during the colonial administration. It started when the Southern and the Northern protectorates were amalgamated in 1914. This problem continued to exist up to post-colonial era, where the military picked up from where the colonial masters stopped. However, all these were because of western cultural ideology that was created by the colonialists that subjected women to domestic responsibilities because of gender differences and some reasons known to them. This problem persisted up to independence period when women were still discriminated in leadership positions. This has created a wide gap that needs to be filled up.

The central argument is that the situation of women in Nigerian Labour Congress generally is that they are marginalized both in membership and leadership positions; they are a vulnerable set of people in the NLC and the society at large. Women have been crying out in recent time and have expressed their desire to be part of the development of the nation: They want to take part in the policy and decision-making process. Obviously, there was a consensus among policymakers, both national and international, that empowering women is a way towards achieving fairness equity and justice in any nation. Empowerment means involvement, participation and having a voice in what is happening in the country. The males have forgotten that "male and female are made to complement 
one another. How then can a nation afford to under-equip and underutilize half of its resources (Women) (Ali, 2014.)".

Moreover, it is contended that women's participation in NLC is very imperative. This is because gender in the Congress is very important, and it matters a lot. Because of this, women need distinct representation to accommodate their needs and aspiration in all the organizations they belong to. Given this, the paper examined women participation in the Nigerian Labour Congress of the Northern and Southern regions. This study attempts to respond to the following research questions:

\section{Research Questions}

The paper answered the following questions:

a) What is the position of women participation in NLC of Northern and the Southern regions?

b) What are the mechanisms that NLC put in place to empower women in the Northern and Southern regions?

\subsection{Objectives of the Study}

The general objectives of the study are to compare the Northern and Southern women participation in Nigerian labour congress with reference to Borno and Oyo states. While the exact objectives are:

a) To examine the position of women participation in NLC of Northern and the Southern regions

b) To reveal the mechanisms that NLC put in place to empower women in the Northern and Southern regions

\subsection{Significance of the Study}

The study is of great significance in two aspects. This is because the research came up with two important contributions: these include academic and practical contribution.

The study is significant in enriching existing literature on gender inequality. Specifically, it helps to identify and filter a myriad of factors affecting women participation in NLC of the Northern and Southern regions. The significant contribution of the study lies in bridging the knowledge and literature gap, and in encouraging Northern and the Southern women to participate vigorously in the union activities like their male counterparts.

The contribution of the study also lies in filling the gaps in the pre-existing works on NLC membership and leadership positions. Gaps are evident as there is still limited study and work regarding the women empowerment as well as their participation in the leadership of labour union, especially in NLC. Scholarly analyses of trade union movement's activities and leadership in Nigeria are more oriented towards the functional and participatory aspects of men. Several studies among different authors focus on the issues related to women's marginalization in the economic and political activities, and their focuses only cover one region. (Abara, 2012; Wabba, 2017; \& Briony, 2017).

In relation to the practical contribution, the outcome of this study would be beneficial to researchers, policymakers, academics, students conducting research in a similar field of study, as well as public and private organizations. The findings of this study can help in policy proposals, which in turn would help in improving the position of women empowerment and participation of the two regions in the trade union movements. The research outcome would contribute to the enhancement of the situation and the position of women empowerment in NLC. It would also serve as a basis for future research on a related topic particularly those that focus on gender-related matters.

\subsection{Scope of the Study}

Considering the broad nature of the topic, and the country under study, this research focus on women participation in NLC, a contrast analysis of gender gap in the Northern and Southern region in the fourth republic. This is because, since the amalgamation of the Southern and Northern Nigerian in 1914, Nigerian constitute two regions, presently, called Nigeria (Mohamed and Allah, 2014). But, due to many states within the two regions, the study focused on Oyo state from the Southern region, and Borno state from the Northern region respectively.

\section{Literature Review and Concept of Gender}

"Gender refers to the biological characteristics that categories someone as either female or male; whereas 'gender' refers to the socially determined ideas and practices of what it is to be female or male (Reeves and Baden, 2000). However, gender is socially constructed and differs from one culture to another. Canadian International 
Development Agency (CIDA'S) policy on 'Gender Equality' (1996) noted that Gender is simply defined as socially built responsibilities and functions of men and women. The concept also comprises the hopes held about the characteristics, attitudes, and likely behaviors of both sexes. According to Wollstonecraft (1988), who is believed to be the first to recognize the social future of male and female, "most differences between the sexes are socially created and not by nature". This assertion is in line with a social constructionist theory, which emphasized that all gender differences that exist in the society are not natural; they are artificially created by individuals in the society.

"Gender is a wide set of features that distinguish between male and female entities in societies extending from the idea of biological identification or sex in humans." In ordinary speech, gender is used interchangeably with "sex" to denote the condition of being a male or female. However, in sociological terms, gender has undergone a lot of debate as efforts have been made by scholars to differentiate between sex and gender; that 'sex' refers to the "organic division into male and female and 'gender' to the parallel and socially unequal division into femininity and masculinity. Gender can, therefore, refer specifically to "socially constructed and institutionalized differences and unequal relationship between men and women in societies (Cobble, 2012)".

However, the term gender has been defined by different scholars based on their perception and understanding. Gender in the context of this paper is defined as some physical and mental attributes that differentiate male from female, and these features are biological in nature.

Gender inequality is mainly the consequence of human behaviour that negates people their human rights (Rahman, Chaudhry and Faroog 2018). The denial of women from rudimentary liberties concludes unexpected costs for society in terms of lower human capital, lower growth and bad administration (World Bank 2001; Sen 1999 as cited in Rahman, Chaudhry, and Farooq 2018).

\subsection{Women in the Pre-Colonial era and Colonial Administration}

Nigeria has a deep root in colonial history, women marginalization first started and imposed by colonial masters in African nations. It begins with the colonial administration, starting with the amalgamation of two protectorates i.e. the Southern and the Northern protectorates (Yoruba and Igbo in the Southern and western parts and the Hausa/Fulani in the Northern part) to the Nigeria's independence and its governance, and then to the postindependence (Adu,2008).

In addition, Adu (2008) noted that Women in the pre-colonial period played a significant role in the political party of the nation. In the different regions of the country, women were actively engaged in politics and took part in decision-making in the traditional institutions of their various regions. But colonial masters created political subjugation that sidelined the women from holding political and elective offices during colonialism. In a related development, Ajayi (2007); Momoh (2008) and Agbalajobi (2010) showcased that in the pre-colonial era, culture, ethnicity, and religion played a very substantial part in shaping the political atmosphere of Nigeria. Yet women were not adequately absorbed in the political and administrative arrangement of the country. In a similar opinion, Momoh (2008) pinpointed that women's duties in the African context are traditionally housewives instead of donating to the development of the economy of the society. This is true from a common Igbo adage that sees wives as 'oriaku' "literally meaning "sit back" and enjoys your husband's wealth."

Scholars such as Mbamalu (2016) and Allen (1972) have gone to a large extent to explain that women were not politically lowered in the Nigerian context, but with the coming and introduction of the colonial system of government after 1900 they were relegated and politically discriminated. Their previous political roles became very low as the colonial rule created a patriarchal government in which women were subjugated to domestic responsibilities and not allowed to hold any administrative position. This argument is not in line with the assertion of the Liberal Feminist Theory, which centered on gender fairness among men and women in every context. . Liberal Feminist believes that both genders are equal and deserve equal treatment.

In the work of Adu (2008) colonialism contributed significantly to women marginalization in Nigeria. As mentioned earlier, colonialism in Nigeria destroyed most of the available institutions in all regions. The British system of administration had misconceptions of operating the administrative system in both Hausa, Igbo and Yoruba land. However, Okonjo (1975) describes the western administrative system in the African societies, more especially Nigeria as "the last retreat of barbarism and tyranny a land where rules were oppressed and resources are exploited. 
Furthermore, Adu (2008) suggests that the period of male governance needs to come to an end. Moreover, Okonjo (1975) makes a similar observation and suggested that in order to bring an end to male domination over the women much need to be invested into education so as to educate and encourage women to take part in a leadership position. It is noted that African leaders were being downgraded by international organizations, which include International Monetary Fund (IMF), the World Bank (WB) and G7. He concluded that "African men have abandoned Africa leadership, therefore, there is a need to shift the political control base to the women".

Similarly, Agbalajobi (2010) espouses that division of labour on gender could be linked to colonial policy. Though the issue of gender discrimination was invoked during the pre-colonial era but was more pronounced by the colonial institutional settings in the post-colonial administration. A study by Ajayi (2007) clarifies that right from independence Nigerian women have been denied chances of assuming political headship at all stages of authority in the nation's local, state and federal government set up. This was as a result of the colonial ideology of male domination over women. This ideology is not in line with Empowerment and Liberal Feminist theories that dwelled on gender equity in all societies.

\subsection{Causes of Gender Discrimination and Violence against Women}

Gender imbalance is not associated with Nigeria alone. It is a phenomenon that affects all societies across the globe, and it is found in all facets of the daily activities with women more prone to poverty, maternal mortality, unemployment, illiteracy, among others. According to the United Nations (UN) statistics "women perform twothirds of the world's work; women earn one-tenth of the world's income, women are two-thirds of the world illiterates (Momoh, 2009). So far, it is noted that women formed half of the world's population but owned only one percent of the world assets. It is also understood that women are frequently exposed to numerous forms of mental, sensual and emotive ferocity. As a result of inequality in power sharing in the society, and between male and female and the influence of patriarchies or patriarchal norms that support inequality. The above mentioned are forms of violence against women as grouped by the United Nations Development Fund for Women (UNDFW, 2006).

Nigerian women are confronted with numerous restrictions in the exercising of their civil rights. Women's liberty of movement is limited in that they are grateful to get their spouses' approval to get a visa or to travel outside the nation. The practice of "purdah", whereby women are isolated from the public space is widely practiced among the Muslim community in the Northern part of the nation. Women in purdah cannot move out of their community freely without the husband's permission and must be accompanied by a close relative when the need arises. Purdah also restricts women's freedom of dress in that Muslim women must be veiled in all public places. Widows in some regions of Nigeria face the utmost degree of marginalization; they are limited to home activities and must keep their heads shaved and wear grief or mourning clothing (Ali and Hamidu, 2016). This view is not in line with Empowerment Theory, which suggested that both men and women should be empowered and shall have access to welfare services such as education and health services. This would help in empowering them and encourage them to control production factors and to participate in decision making.

\subsection{Women in Administration}

A study by Anugwom (2009) observed that the patriarchal settings of the society is one of the main limitations impeding the women development in education. Therefore, he is of the opinion that most of the educational and administrative sectors are organized and dominated by their male counterparts. In addition to that, the authorized body founding administrative work, their time of meetings functions, and their administrative activities are frequently personalized to the men only, without considering the nature of women activities in the society. This is because some women are assigned dual responsibilities (i.e. domestic and union responsibility). Consequently, the activities are not formed with the purpose of taking women to be "commanding them". Because of this, they find it hard to perform their functions actively in the administration process. This is as a result of their educational background. To support the argument, a study by Parpart (1988) labels the administrative structure as 'patriarchal ideology' which denies women's involvement in most of the trade union activities. Considering the Nigerian condition. Ubeku (1983) argues that the societal customs and traditions do not support the women to lead men in all spheres of lives. It is further noted that women in the labour union are being intimidated by their male's counterparts. There is the existence of subtle intimidation of the female members of labour unions by their male counterparts. This problem of intimidation by the males coupled with the fear of the men anger has made women to restrict themselves to the domestic assignment. The intimidation of women by the men is against the postulations of 
the Liberal Feminist Theory, which believes in gender equality among men and women in every society as well as in organizations.

Nevertheless, it is known that Africa is patriarchal in nature; however, the main block of patriarchy was wrecked when African men finally started agreeing to take women as contemporaries and partners in progress in the workplaces. With this development, one would expect more women in political and administrative positions. While the remains of patriarchy exist in their rowdy nature, the real problem lies in the lack of women determination towards administrative positions in trade unionism in Nigeria Momoh (2009) argues that "women have regarded administrative activities as the prerogative of men". Over the years, they have dreaded union affairs due to the personality clashes, hostility, and hooliganism displayed by the men (Momoh 2008). The problem was further worsened by the attitude of some women workers, who are not willing and interested to participate in union elections in their offices in order not to offend their proprietors or bosses. In many African nations (Nigerian inclusive) it is noted that gender matters have given rise to the religious, cultural and social context that assigned men a higher position and domination on all power sources (Momoh, 2009).

\subsection{Women Empowerment}

Women empowerment is the ability to train women some important skills to be active and dependent on society. According to Kabeer (2002) women's empowerment is about the procedure in which those who have been deprived in any aspects of life and have the capacity to make planned life choices acquire such capacity. Empowerment means ways that involve some series of stages through which individuals or group of people become conscious of their rights and privileges to protect their rights. By taking these stages, the individuals increase their living standards such as health, education and economic condition. Empowerment is a process which allows people to significantly advance their living standard (Menhas, \& Yaqoob, 2013).

\section{Empowerment Theory}

Empowerment Theory is concerned with the process of empowerment which covers five stages: welfare, access, conscientization, participation, and control. In this case, Conscientisation refers to the first level and is the beginning of empowerment because the women realize that they are being disadvantaged not due to their inability but due to their gender. So, therefore, the theory centered on women empowerment and gender fairness in society. The theory is concerned with the understanding of discrepancy between sex and gender, and consciousness that gender characterizations are traditions and can be altered. 'Conscientisation' believes that the sexual division of labour should be fair and agreeable among men and women. Given this, the theory calls for women empowerment and gender equality. This can be accomplished through the levels of empowerment as mentioned earlier (Longwe, 1990).

\subsection{Liberal Feminism}

To support the empowerment theory, the study used liberal feminist theory. The theory is much concerned with gender equality that men and women were born equal and should be given equal treatment and deserved fairness in all aspects of life endeavours. The liberal feminist theory thus is consistent with the dominant American ethos in its basic acceptance of democracy: Its appeal to the value of individualism, choice, responsibility, and equality of opportunity. The theorists do not seek revolutionary changes in society. but rather they want reforms within the existing social structure (Rubery, 2002).

Feminist's philosophers have contended that in any patriarchal civilization, be it outdated, industrial or collective, a system of gender and monetary system function concurrently. They described patriarchy as a not fair system that is cruel to womenfolk. As an egalitarian and political thinker Carole (1989) wrote, "The patriarchal shape up the modification between male and female the political change of domination and freedom."

\section{Method of Data Collection}

The study adopted both interview research method and available documents. For the survey, the interview was used to extract information from individual participants. So, the secondary data was, however, gathered through the survey of relevant published and unpublished materials in the bibliographical sections of various libraries (John W. C., 2009). In the case of the interview, data were collected from 14 participants seven from each region.

Theses fourteen participants were purposively selected to represent the entire Congress. Participants were chosen because of their position and the knowledge they have on the union matters. The justification for using only 14 
participants is that the researcher has reached a saturation point where the participants have started repeating the data. Saturation refers to the situation where the participant has no new information on the research questions under investigation (Creswell, 2009).

\subsection{Research Design}

This study is a Case study because it provides an in-depth understanding of the social phenomenon, or it helps in providing an in-depth understanding of a case or cases. It also assists in studying an event, or a program, and activity through numerous sources (Creswell, 2013).

\subsection{Method of Data Analysis}

All the data generated through the interview and relevant literature were analyzed thematically using MAXQDA 2018. In the courses of the analysis, the study uses a contrast analysis approach in comparing the position of women participation in NLC of the Northern and Southern regions. It further compared the mechanisms uses in empowering women in the Northern and Southern regions (Herv'e Abdi \& Williams, 2010; Marshall, \& Rossman, 2006;).

Table: 1.1: Demographic Data of the Participants

\begin{tabular}{|l|l|l|}
\hline Demographic & Features & Number \\
\hline Age & $20-30$ & 3 \\
\hline & $31-40$ & 3 \\
\hline & $41-50$ & 5 \\
\hline Qualification & $51-60$ & 3 \\
\hline & Secondary School Certificate & 2 \\
\hline & Diploma in Education & 2 \\
\hline & $\begin{array}{l}\text { Nigeria Certificate in } \\
\text { (NCE) }\end{array}$ & 5 \\
\hline & Degree & 2 \\
\hline Gender & Masters/ Ph.D. & 11 \\
\hline & Male & 3 \\
\hline Occupation & Female & 14 \\
\hline Total & Civil Servants & 14 \\
\hline
\end{tabular}

Source: Field Study (2017)

\section{Findings}

Considering the nature of the topic investigated, the study, therefore, merits to compare women participation in the Northern and Southern regions in Nigeria, focusing on Oyo and Borno states, respectively. The justification for Borno state is that it is one of the educationally developed states among the Northern states, considering the women population in the workforce in the state but does not correspond with the strength of women in the NLC. The effort of the government in investing much in education by establishing public schools across the state as one of its plans to encourage both men and women enrolment in education by giving free education to both genders. This is in line with Empowerment Theory, which centered on empowering both genders in the nation, by allowing them to have equal access to welfare services. But the level of women in education is at the minimal, which eventually affects women in public service and labour Congress at large, compared to women education in the Southern region, precisely Oyo state. Borno state is patriarchal in nature, which marginalized women to domestic up keeping. This is against the postulations of Empowerment and Liberal Feminist Theories, which believe in gender fairness among the sexes in all societies.

In terms of education, the paper found that the first university in the Northern region was established in 1975 in Borno state, and in 2016 the state government make it two with the establishment of another University in Borno state. Still, Borno state women are unlike their Southern counterparts that are westernized, educationally sound and empowered. The justification for Oyo state is connected with the view of Logbaby (2000, 2007). Oyo state was first colonized by the British people before the colonization of the Northern region. And the first Nigerian University was established in Ibadan, so, western education was first started in the Southern region. That is why the Southern women were more educated, exposed and empowered than the Northern women. In addition to this, the state was 
the center of administration in the old western region, and it is homogeneous in outlook, unlike Borno state that is heterogeneous in nature. Considering the Atlantic Ocean in the Southern axis of the nation, the Southern region becomes a strategic center for commerce and industry. However, it is also blessed with abundant natural resources like Clay, Kaolin, and aquamarine.

It has been debated by numerous researchers that women, by nature of their representation in the NLC in the Southern states, have brought diverse and broader matters into labour movements, influenced the strategy output to be sociable, and altered the environment. This has stimulated some womenfolk to vigorously get involved or participated in labour movements of the Southern region.

\subsection{The Position of Women in NLC of the Northern Region (Borno State)}

The study found that women are part and parcel of the NLC of the Northern region, but their position in the labour union of the region is very low because of the culture, patriarchal and religion nature of the region, that designed and assigned domestic responsibilities to women. This was disclosed by the participants, who explained that women in the Northern region are less active in labour matters because of the family background and religion inclinations that do not support women to take part in the labour activities. Out of the eleven positions, only two are females while nine are males. To support the above assertions, another participant opined that some parents in the Northern region sees it as a taboo for a female to take part in the labour activities because NLC comprises both men and women. This opinion contradicts the assertion of the Liberal Feminist Theory, which believes that both genders were born equal and need to be treated equally in the society.

Table: 1.2 Illustrating the Positions Occupied by Women in NLC of the Northern Region (Borno State)

\begin{tabular}{|l|l|}
\hline Chairperson & Male \\
\hline Vice-Chairperson & Male \\
\hline Treasurer & Female \\
\hline Secretary Finance & Female \\
\hline Secretary & Male \\
\hline Assistant Secretary & Male \\
\hline Assistant Secretary Information & Male \\
\hline Secretary Welfare & Male \\
\hline Auditor I & Male \\
\hline Auditor II & Male \\
\hline Public Relation Officer (PRO) & Male \\
\hline
\end{tabular}

Source: Fieldwork (2017); AUPCTRE (2017).

From the above table, it is understood that women occupied only two positions in the NLC of the Northern region, precisely Borno state. The positions occupied by women are invariably that of the treasurer and the financial secretary. This is because the men have confidence in the women's prudence in financial and record keeping, and this was exposed by the participants. They all believe that women can hardly mismanage the union fund.

\subsection{The Position of Women in NLC in the Southern Region}

The position of women participation in the labour union of the Southern region was believed to be active. This was expressed by the participants, unlike the position of women in the labour union of the Northern region. For instance, in the Southern region, precisely Oyo state, a labour movement has eleven posts, out of these eleven positions seven are occupied by males and four by females. This signifies that women are active in the NLC of the Southern region compared to the women in the NLC of the Northern region. Similarly, another participant showcases that "in the Southern region they used to leave some position for women like financial secretary or treasurer, so I don't know if is applicable to NLC in the Northern region". 
Table: 1.3 Showing the Positions Occupied by Women in NLC of the Southern Region (Oyo State)

\begin{tabular}{|l|l|}
\hline Chairperson & Male \\
\hline Vice-Chairperson & Male \\
\hline Treasurer & Female \\
\hline Secretary Finance & Female \\
\hline Secretary & Male \\
\hline Assistant Secretary & Male \\
\hline Assistant Secretary Information & Male \\
\hline Secretary Welfare & Female \\
\hline Auditor I & Male \\
\hline Auditor II & Female \\
\hline Public Relation Officer (PRO) & Male \\
\hline
\end{tabular}

Source: Fieldwork (2017); (AUPCTRE, 2017)

The table above depicts the positions occupied by a female in the NLC of the Southern region, precisely Oyo state. Women occupied four positions in the NLC of Oyo state. The positions occupied include: the treasurer, financial secretary, secretary welfare and Auditor II. This was disclosed by the participants, who added that women in the NLC of the Southern region are participating in the labour movement because of education, exposure and desire to take part in the labour activities. .

\section{Discussion}

This section of the paper discusses the results of the findings on women in NLC of the Northern and Southern regions. Nigerian women have come across several difficulties while volunteering in labour activities more especially in the Northern region. There is a wide discernment from the men counterpart, in electing an aspirant, allocating political offices or taking part in any union of their choice. Often, males constitute a higher proportion of the membership in the union and this tends to affect women when it comes to empowerment, participation and electing or selecting labour leaders. Meanwhile, the study discovered that men have the highest proportion in the union membership and leadership; they tend to control the union positions, therefore, have the advantage in persuading labour politics. These findings are not in line with Empowerment and Liberal Feminist Theory that dwelled on gender fairness among men and women. Empowerment Theory suggested that both genders should have equal access to welfare services; they should involve them in the decision-making process in societal matters.

The study found that women in most of the cases constitute a lesser fraction of the labour movements in the Northern part of the country because of the cultural, religious and social attitudes of the societies, which most frequently demote women to the subordinate positions. Because of this, only a few men, even among the educated, allow their companions to come out to take part in the labour movements.

Another challenge confronting women in labour unionism is an inadequate education. It is observed that women constitute a greater ratio of the uneducated group in the Northern part of Nigeria, unlike the Southern women, who believe in education. This is first because of the family background. Most of the parents in the Northern part of the country prefer to educate their male children then their female ones whom they believe will later get married to another family, and therefore, get united into another family. Therefore, a greater number of women go on unschooled and not exposed to labour activities. These findings do not correlate with the beliefs of the Empowerment and Liberal Feminist Theory that centered on gender equality among men and women.

Lack of financial power is a factor to participation and women empowerment in labour activities in the Nigerian context, precisely in the Northern part of the country. The study instituted that most of the Northern women are not financially sound compared to their Southern counterparts that are financially sound. It is also understood that family or household tasks such as childbearing deter women from participating effectively in labour matters. During their adult lives, most women are involved not only in childbearing but also in child nurturing. Hence, much of the time they may have wished to devote to labour activities are taken up by their maternal tests and responsibilities. 
It is also found that several factors were noted as a hindrance to women participation in labour activities of the Northern region. These problems explained what is responsible for the arbitrary rate of exclusion of women from unionism in the Northern part of the country, and why few of them hold a position in the union of their choice.

Poverty is another factor to women participation in labour movements: The study found and disclosed that women are not financially buoyant especially in the Northern region where most of them depend on their husbands and parents, as such, they don't have the financial power to compete with the men in union matters. Though women in the Southern region are a bit okay financially, because most of them are not dependent on their husbands or parents, they also struggle like their male counterparts. However, to overcome the women economic set back, Empowerment Theory suggested that both genders need to be empowered by giving them equal treatment in terms of welfare services in the nation. This will encourage them to be involved in the decision-making process and policy implementation. To support the argument, a study by Rahman, Chaudhry, and Farooq (2018) pointed out that educating women is significance in poverty reduction. In this case government should provide all genders with free education, precisely to girls and children from poor background, and they should be given monthly stipend. This would encourage them to send their children to schools, especially the female's ones.

Some social socio-cultural factors such as religion contribute in subjugating women from taking part in labour related matters especially in the Northern part of the nation. This has accounted for some of the strategies used in excluding women from the labour movement, precisely in the Northern part of the nation. However, the study showcased that in the Northern parts of Nigeria women are secluded and not allowed to participate in any public matters like labour movement. For instance, in the Northern part of the country, it is understood that an important factor inhibiting women's participation is the religion (purdah system i.e. house seclusion of women). This result contradicts the postulations of Liberal Feminist Theory that believes in gender parity among both genders.

It is observed that women cannot lead but to be led. This is because of some cultural provisions that are not in support of women to lead, and which subjugated them to subordinate position.People in the north believe that women position is at home to take care of the young ones and to prepare meals for the entire family. With these stereotyped roles, it is difficult for women to participate in labour unionism since they are restricted to the private sphere. Therefore, men do not see or accept women as leaders. Similarly, any woman who aspires to do those things that men do (unionism for instance) is seen as "cultural or religion deviant." Some women are seen by men as being assertive or outrageous.

The study pointed out that most of the Northern women are not educated., This put them at the subordinate position. Women also were subjugated to lower positions because of their low level of education. However, the percentage of educated women has increased in recent time in Northern parts of the country. In the past, people believed that women should be married at the earlier age to produce and raise children and take care of the husband, which is against the assumptions of Empowerment and Liberal Feminist Theories, which are concerned with gender equity among all sexes.

Participatory time constraints: The study noted that time is an important factor for women participation in NLC. So, the study found that most of the time allocated for the union meetings are not favourable to women. This is because of the nature of their dual responsibilities and marital duties that need ample time to execute them. This means most of the women's time are assigned to domestic work. In most of the cases women have less time for the union activities. In addition, most of the union meetings are scheduled to hold in the night time, which is against the marital obligations and regulations, and against religions and cultural doctrines of the Northern region.

\subsection{Mechanism and Strategies to Empower Women in the NLC}

The study found that there are internal and external mechanisms to empower women in the NLC of the Northern and Southern regions. Under the internal mechanisms, education, women committee, women commission, motivation, and gender policies are some of the strategies and policies used in empowering women to participate actively in the union activities of the two regions under investigation. Here, the paper discussed the mechanisms, policies, and strategies to empower women to participate actively in the NLC of the Northern and Southern regions. Moreover, the study found that international agencies play an important role in empowering women in the NLC of both regions. These agencies include international labour organization, international conventions, and Geneva affirmative action among others. Women commission and women committee are constitutionally formed to 
empower women in the NLC of both regions but are more effective in the Southern region because of exposure and education background.

Education is found to be one of the major mechanism to empower women to participate actively in the labour movements of the Northern and Southern region. The study discovered that women in the Southern region were educated compared to their counterparts in the Northern region. This is because women in the south were exposed to Bible schools, Harmattan school, Rain school and Institute of Labour Law Management Relation, among others. However, it is observed that women in the Southern region were educated through the above-mentioned institutions, Because of this, the study found that the least among educated women in the Southern region is secondary school leaving certificate, unlike women in the Northern part that were marginalized to the domestic responsibilities at the household. This finding is in line with Empowerment Theory, which buttressed that both genders should have equal access to welfare services such as education and health services.

Harmattan School is one of the mechanisms NLC put in place to empower women in the NLC of the Northern and Southern regions, though is more functional and effective in the Southern region. This is because women in the Northern region are being subjugated to domestic activities because of the patriarchal nature of the region that everything is managed and controlled by the men. Harmattan School is an institution where union members attend in order to acquire knowledge of labour activities.

Rain School was provided by the NLC as a strategy to empower their members on the labour movements. This School operates mostly from November to December annually. However, the institution is in the Southern region. That gave the Southern women ample opportunity to attend the school and take part vigorously in the labour unionism of the Southern regions. But women in the Northern regions find it difficult to attend because of remoteness, lack of interest, marital status, and pregnancy, among others.

The paper later disclosed that gender parity is necessary for attaining educational goals and objectives that will bring about maintainable development possible. Professionals detected that economic growth and education are the two key Sustainable Development Goals (SDGs) and the most significant for the remaining objectives to be accomplished. Recently, a report from the International Monetary Fund (IMF) notes the importance of gender fairness to economic development which is attained through investing in educational sector. This is because gender parity yields public-private returns, and backup both economic and social development. The development of international social justice and the human rights program, and their welfares extend to people, relations, groups, and humanity at large.

Workshops and Seminars are other strategies used in empowering women to participate actively in the labour movement of the Northern and Southern regions. The study noted that Southern women are actively participating in the NLC because of their education background and through workshops and seminars being organized by the NLC of the Southern region.

The Aba women riot of 1929 also encourages women to participate in the labour movement of the Southern region. When the Southern women watched the 1929 Aba riot movies organized by their fellow women on taxation policy, that gave them the courage and morale that women can do what the men are doing even better.

The study found that gender policies and strategies are what empower and encourage women to participate actively in NLC of the Northern and Southern regions of the country. This was explained by the participants at the interview session. They all revealed that education and gender equality among men and women in the society would encourage and empower women to actively participate in the labour movements of the Northern and Southern regions, and it will as well lead to economic and social development in the society.

It is understood that most of the women are not actively participating in the NLC because of poverty. The study found that women are low-income earners, which is why they are not competing with their male counterparts for a position in the NLC. But this is mostly found in the Northern region; women from the Southern region are well empowered, and they compete with the men for any position in the NLC of the region.

This coincided with the submissions of the Global Partnership for Education (2016) that gender-responsiveness must be the main precedence throughout the work of the Global Partnership for Education, given the massive joint 
status of gender equality and education. As the international community has become gradually conscious, education plays an important role in understanding development to gender fairness for authorizing girls and boys with basic skills for work, increasing livelihood opportunities, influencing and autonomy, knowledge and skills for leadership capacities.

\section{Limitation of the Study}

The study has some limitations because the study focused only on two regions and precisely two states (Borno and Oyo) all in Nigeria, hence and certainly, a generalization cannot be ruled out. The qualitative method was limited to a sample of fourteen participants. Again, the participants did not cover all the thirty-six states of the country. However, this study does provide an in-depth understanding of certain localities and a certain type of people, in this context, women in NLC in the two regions (Borno and Oyo states).

\section{Recommendation for Future Research}

This research work recommends future research to broaden the body of knowledge in the literature of the position of women participation in the NLC. Subsequent research could explore other different unions or associations. The quantitative study could be conducted to enable researchers to drive generalization in some aspects relating to women participation and empowerment in NLC. A comparison will be much more meaningful if men are also incorporated as subjects of investigation.

\section{Conclusion}

The study concludes that the position of women participation in the NLC of the Northern region is low compared to the position of women participation in the NLC of the Southern region. This is so because several mechanisms and strategies were employed by the NLC of the Southern region in empowering women. This is because of their educational background and exposure compared to the women in the NLC of Northern regions most of whom are not educated and are being controlled by religious and cultural inclinations. The paper concludes that since NLC comprises both genders, women should equally participate in its decision making and implementation of policies in the NLC of both regions. It then concludes that women are underrepresented in the labour unionism of both Northern and Southern regions but is more pronounced in the NLC of the Northern region.

Finally, the study noted that women in the Southern region were empowered through different kinds of NLC programs, such as training like skills acquisition and capacity building that help in empowering them to participate actively in the labour activities movements. In this junction, it is discovered that women in the Southern region are more empowered than their Northern counterparts who are mostly restricted at home to look after the young ones and to prepare meals for the family. More so, the researcher, in addition to the above, completes that women in the Southern region were opportune to attend seminars and workshops in line with the NLC programs, to empower and encourage them to actively participate in the union activities of the Southern region.

\section{Recommendations}

The paper came up with the following recommendations:

- The government should establish and implement poverty alleviation programmes at all three tiers of government to empower women.

- The government should initiate women empowerment schemes that would empower women in all regions.

- A credit scheme should be established for women and it should be under the control of women organization.

- PDP policy that women will be refunded the money used in contesting elections should be implemented in the labour union. This policy should serve as a morale booster.

- Inverse marginalization of women is the finest process to improve the participation and empowerment of women in NLC. In this case, the government creates a strategy by allocating a free and mandatory seat to women. This would encourage them to take part in the NLC of both regions

- Women issues and problems and ways to enhance them should be deliberated through women wing and should be used as the medium of discussing issues related to women in the NLC of both regions.

- All union meetings should be carried out in the daylight, not in the night time, and it should be in the union offices, not private housing. This is because many spouses would not permit their wives to attend any union meeting in private houses or in the night time.

- The government should help in educating women by giving them free education, especially in the Northern region where women are less educated and not adequately participating in the NLC of the region. 
- Government and NLC should engage in enlightening women on the importance of their participation in the union activities in all regions.

- Religion and traditional rulers should discourage culture and traditional norms that sidelined women to domestic activities.

- Parents and spiritual leaders should help in enlightening women on the significance of women participation in NLC of both regions because they can represent the rights and interest of their female members in the labour unions.

- To encourage women to take part in the labour unionism, all parents and the community elders should assist in encouraging them on the necessity of women participation in the labour activities of both regions.

- To encourage women to participate actively in the labour activities of the Northern and Southern region, there is a need for proper and adequate orientation on the significance of women participation in NLC.

- NLC should establish Harmattan and Rain Schools across the nation to educate women on issues related to labour activities.

\section{References}

Abara, C. J. (2014). Inequality and Discrimination in Nigeria Tradition and Religion as Negative Factors Affecting Gender. Federal Ministry of Culture and Tourism Nigeria, pp. 1-18.

Adu, O. (2008). The Missing Link: Women' s Representation and Participation in Nigeria' s Electoral Politics and their Effects on Nigeria' s Development .

Agbalajobi, D. T. (2010). Women's participation and the political process in Nigeria: Problems and prospects. African Journal of Political Science and International Relations, 4(2), 75-82.

Aiyede, E. R. (2004). United we stand: labour unions and human rights NGOs in the democratisation process in Nigeria. Development in Practice.

Ajayi, K. (2007). Gender self-endangering: The sexist issue in Nigerian Politics. Social Sciences, 14(2), 137-147.

Ali, A. M. (2014). An Assessment of Factors Affecting Women Participation in the Nigerian Labour Congress. Journal of Emerging Trends in Educational Research and Policy Studies, 5(8), 220-223.

Ali A. M. and Hamidu I. (2016). An Assessement oF the Factors Affecting Women Participation in Trade Union Activities in Yobe State, Nigeria. Administration and Development Studies, 6(1), 236-252.

Allen, J. (1972). " Sitting on a Man ": Colonialism and the Lost Political Institutions of Igbo Women. Canadian Journal of African Studies, 6(2), 165-181.

Anugwom, E. E. (2009). Women, education, and work in Nigeria. Educational Research and Review, 4(April), $127-134$.

AUPCTRE. (2017). Amalgameted Union of Public Corporations, Civil Service Technical and Recretional Services Employees.

Briony, H. (2017). What is the gender gap (and why is it getting wider. World Economic Forum.

Carole, P. (1989). The Disorder of Women Democracy, Feminist and Political Theory.

Cobble, D. S. (2012). Gender Equality and Labour Movements : Toward A Global Perspective, (February), 1-71.

Creswell, J.W. (2009). Research Design: Qualitative, Quantitative, and Mixed Methods Approaches. London SAGE Publication, Incoporated.

Creswell, J. W. (2013). Research Design: Qualitative, Quantitative and Mixed Method Aproaches. SAGE Publications.

Global Partnership for Education. (2016). Gender equality policy and strategy 2016 - 2020.

Hazel Reeves, and Sally Baden. (2000). Gender and Development: Concepts and Definitions. Institute of Development Studies (Vol. 30). Retrieved from http://www.ncbi.nlm.nih.gov/pubmed/2882069

Herv'e Abdi, \& Williams, L., J. (2010). Contrast Analysis (2010).

John, W,. C. (2009). Research Design Qualitative, Quantitative and Mixed Method Approaches.

Kabeer, N. (2002). Resources, Agency, Achievements: Reflections on the Measurement of Women's Empowerment.

Logbaby. (2000). History of oyo states, Nigeria.

Logbaby. (2007). Borno State, Nigeria (Overview, History and Summary Information).

Longwe, S. (1990). Gender link for equality and justice.

Marshall, C., \& Rossman, B. (2006). Designing qualitative research. Sage Publication.

Mbamalu, B. C. (2016). Challenges and Prospects for Women in Constitution-Building in Sub-Saharan Africa: A Comparative Study of Rwanda, Kenya and Nigeria.

Menhas, R., Jabeen, N., Akhtar, S., \& Yaqoob, M. (2013). Cultural Barriers of Female Empowerment. Afro Asian Journal of Anthropology and Social Policy, 4(1), 1-10. 
Mohamed, A., \& Allah, H. (2014). The Role of the Nigerian Labour Movement in the Democratic Transformation. African Pespectives, 12(41), 30-38.

Momoh, A. M. (2008). Nigeria, Gender Participation In Trade Unionism In Southwest. International Journal of African \& African American Studies, 7(2).

Momoh, A. M. (2009). Gender Participation In Trade Unionism In Southwest Nigeria. African American Studies, $7(2), 10-24$.

NLC. (2017). The Nigerian Labour Congress Hand Book, 1-37.

NLC Report. (2016). Nigeria Labour Congress (NLC).

Okonjo, K. (1975). The Role of Women in the Development of Culture in Nigeria. In women cross culturally, Ruby Rohrlich-Leavitt (Ed) (pp. 31-39).

Parpart, J. L. (1988). "Women, Work and Collective Labour Action in Africa" Labour and Unions in Asia and Africa. London; Macmillan Press LTD.

Rahman, S., Chaudhry, I.S., Farooq, F. (2018). Gender Inequality in Education and Household Poverty in Pakistan : A Case of Multan District. Review of Economics and Development Studies, 4(1), 115-126. https://doi.org/10.26710/reads.v4i1.286

Rubery, J. (2002). Gender mainstreaming and gender equality in the EU: the impact of the EU employment strategy. Industrial Relations Journal, 33(5), 500-522.

Ubeku, A. K. (1983). Industrial Relations in Developing Countries: The case of Nigeria. London, Macmillan Press. UNDFW. (2006). United Nations Development Fund for Women.

Wabba, A. (2017). Address of the President of Nigerian Labour Congress, to Opening Session of the 4th National Gender Conference of NLC,

Wollstonecraft. (1988). The Pedagogy as Self Expresion by Exocising the Past, Findings a Voice. The Private Self Theory and Practice of Women Autobiography Writings (pp. 193-195). 